\title{
Editorial
}

\section{Responsible Practice of Research: Safeguarding Research Integrity and Publication Ethics}

\author{
Rebat Kumar Dhakal* \\ School of Education, Kathmandu University, Lalitpur, Nepal
}

\section{Opening}

In recent years, there has been an outburst of general interest on how we do 'research' (Bossi, 2010; Lins \& Carvalho, 2014) - right from planning to reporting results - and how we disseminate 'knowledge'. This rise of interest has particularly resulted from the surfeit of news on dishonest practices of research community. Some of the 'acts of wrongdoing' or fraudulent research practices that arise in our academic debate comprise the cases such as creation of false data or manipulating data to generate preferred results, cheating or using other's ideas as own, disclosing improperly the identity of participants, underserved authorship claims, submission to multiple journals, duplicate publications, salami slicing, and predatory publications. In fact, these practices pose a serious question on research integrity. But what actually is 'integrity' in research?

Research integrity or scientific integrity as a concept is difficult to define precisely because expected behaviours for professional conduct are subject to reinterpretation (Steneck, 2002). Being aware of the fact that there are epistemic distinctions between and among similar phraseology, we often use "research integrity", "scientific integrity", and "research ethics" interchangeably. Not flouting Steneck's (2002) remarks, I however, try to draw from some extant definitions here. For Macfarlane (2009), research integrity is the consolidation of a researchers' personal values, norms and identity with their professional practice as a researcher. However, integrity goes beyond a researcher and touches upon the research institution and the research community alike. Covering both individual and institutional aspects, the Norwegian National Research Ethics Committees (2016a) conceptualise research ethics as "a diverse set of values, standards, and institutional arrangements that contribute to constituting and regulating scientific activities" (p. 5). Research integrity can also be defined as the adherence to a code of moral values and professional ideals in scientific endeavours (Alper, 2008), as framed by the research 
institutions (Steneck, 2006). Yet, this is not very helpful, since it also leaves room for doubt: will any standards and criteria an institution develops guarantee research integrity?

What the above definitions hint us, however, is that we need to have some practical situated guidelines on research integrity, and even then, the guidelines cannot be all encompassing since integrity is basically a moral attitude, which warrants moral deliberation, critical reflection, self-discipline, moral choice and accountability (Bossi, 2010; Edwards \& Mauthner, 2012) on the part of the researchers and the entire research community. Exploring further, I find the U.S. National Institute of Health's (2012) definition more encompassing which defines research integrity as including "the use of honest and verifiable methods in proposing, performing, and evaluating research; reporting research results with particular attention to adherence to rules, regulations, and guidelines; and following commonly accepted professional codes or norms" (para. 1). Khanyile et al. (2006) also attest to this definition who consider research integrity as "justice and honesty in proposing, conducting, and reporting research" (p. 41). Ruminating on all these definitions, I deduce that having some sort of ethical consciousness while engaging in any research activity is the crux to doing a 'good' research. And as such, research misconduct or scientific fraud, which stands opposite to research integrity, is perceptibly a violation of research integrity.

Putting aside all these expert definitions, I would like to reflect what we actually mean when we use these terms in our ordinary way of speaking. For me, one of the most common-sense meaning of integrity is the quality of being honest and morally guided in our thoughts and actions. As such, it usually refers to the virtues like 'honesty', 'probity', and 'ethics' (Committee on Assessing Integrity in Research Environments, 2002). What comes to our mind so readily about integrity is honesty, sincerity, fairness, and responsibility (Parizeau, 1999). And when we see this word in connection with scientific inquiry, it can be construed as moral values held and behaviours demonstrated by the researchers while undertaking any research activity. Integrity in academic research context therefore broadly means acceptable scientific behaviour in the conduct and reporting of research. These definitions rather than defining what actually research integrity is, give us ideas for developing customary codes of professional ethics so as to prevent research misconduct.

Probably, the commercialisation of research has led scholars to shift the focus from promoting research integrity to checking misconduct. As a result, most literature explains research integrity in terms of avoidance of misconduct (Khanyile et al., 2006). In fact, integrity and misconduct need to be seen in a spectrum - "where research integrity ends, research misconduct starts" (Khanyile et al., 2006, p. 40). But it is important to question why research misconduct occurs in the first place? What makes researchers fall into doing easy research at the cost of doing 'good' research? There could be many reasons to explain this. However, "pressure on researchers to "publish or perish" and the fact that "new technology have made it easier to do research' can be attributed to alluring researchers to 
get into misconduct (Aschwanden, 2007; Lins \& Carvalho, 2014). The current environment of academia and postgraduate programs in Nepal is characterised by pressure on faculty and students to increase scientific production. And we need to be aware that researchers might use unfair research practices to survive the pressure. But why do research committees and institutions turn blind eyes to the scientific misconduct? Is it because they do not know what their ethical standards are or because it is easier not to think about them? Why do some researchers fall prey to journals that publish 'anything' and repent later? And similarly, why journals publish 'anything' and jeopardise their own reputation? Are our moral reasoning, personal ethics, and execution of professional commitment eroding? These and several questions warrant careful reinterpretations at the research institutions time and again, especially in Nepali context where 'standard' research practices (both conduct of research and publication) are yet to mature.

\section{Lighting the Way}

There is no denying that research must be of high quality to build knowledge that not only guides and informs the academic community of practice, but also applies outside of the research community - contributing to social to global development. There is also growing understanding that credibility of research can be debilitated if there is room for doubt against the common ethical norms such as reliability, truthfulness, respect and accountability. Therefore, it is necessary that research is done in ethical ways. Along this line, the entire academia seems to stand for 'responsible conduct of research' (Macrina, 2014; Shamoo \& Resnik, 2015). However, research practice does not stop at conducting only - it goes beyond at least to dissemination, if not making an impact. And that once the conduct of research is completed, it becomes the moral obligation of the researcher to get it published and/or disseminated (Scanes, 2007). This entire process from planning and designing the research to publishing and disseminating research outcomes demands responsible practice from those involved, especially funders, researchers, research institutions, reviewers and publishers. The emphasis of this paper is on the personal (i.e. researcher) and institutional (research promoting institutions including University Grants Commission, universities and research centers) practices in regards to promoting research integrity and publication ethics. Moreover, this paper makes reference of Nepali scholarly context and the field focuses on social science research.

\section{Individual Practices and Responsibilities}

Social science researchers, by virtue of being social forerunners, engage in good research practice who explore social nuances and also inform future course of action. Principally, all researchers should stay away from research misconduct, which means fabrication, falsification, and plagiarism in proposing, performing, reviewing, or reporting research results (U.S. Department of Health and Human Services, Office of Research 
Integrity, 2009). They should rather basically adhere to the fundamental ethical norms such as informed consent, reliability, truthfulness, respect (informed consent, privacy, autonomy and anonymity of the participants), impartiality, and accountability. They are expected to demonstrate "a commitment to intellectual honesty and personal responsibility for one's actions and to a range of practices that characterise responsible research conduct" (National Academy of Sciences, 2002, p. 34). They have to refrain themselves from taking part in or being part of any questionable practices (such as allocating co-authorship on false premises, fabricating data, using data selectively, plagiarising - wrong use of the words and ideas of others, and concealing conflicts of interest), whether in the planning, execution or reporting of the research.

It is a common-sense understanding that all researchers have the fundamental knowledge of research ethics. Despite having these basics of research integrity, we often hear and read about researchers getting into some murky jobs. News reporting today frequently suggests that the incidence of misconduct is on the rise. Why does it happen? Are increasing numbers of researchers acting unethically despite having the fundamental awareness that "who betrays science in this way negates the significance of their own existence as a researcher" (Ministry of Education, Culture, Sports, Science and Technology, 2014, p. 1)? If so, are research publications reliable or trustworthy? Can it be profitable to fabricate or falsify results? Has the competitive nature of scientific research placed pressures on scientists that lead to misconduct? What makes researchers publish 'sloppy research' in predatory journals? Or are researchers falling prey to the increasing number of bogus publishers simply because they do not have sufficient knowledge of such business? In fact, recent world has become infected by predatory journals and publishers, fake impact factors and misleading metrics that are launched by bogus companies (Jalalian, 2015) and researchers need to be aware of them. I personally de-emphasise the 'impact factor mania' though that charms so much too many scientists. Moreover, why does authorship debate frequently come across academia? Researchers should be aware of these and similar questions and act ethically to stand for 'good' research that enhances public trust on the research community.

In my observation in Nepali universities, the trend of honorary authorship, which in any case is an unacceptable research practice, is prevalent, and it is comparatively higher in natural and health sciences than in social sciences. In this regard, researchers and also research faculty must be aware of the rules for co-authorship - "when several authors contribute, each authorship must be justified" (Norwegian National Research Ethics Committees (2016b, p. 10). Likewise, plagiarism is paralysing our academia. Moreover, researchers are sometimes unduly influenced by the commissioning agency in their choice of methodology, implementation or publication. These practices are causing great harm to the public trust on research community at large. Therefore, it is the responsibility of the researchers to adopt 'fair' research practices. 
Researchers also have the responsibility to ensure that their research will not cause any harm to the research participants, any group or societies, or the environment, rather they have a duty of care even to readers as they do their participants and funders. They also have the moral responsibility to disseminate their research knowledge "to satisfy the intellectual curiosity of the general public" (Norwegian National Research Ethics Committees (2016a, p. 37). Researchers should disclose financial and other conflicts of interest that could compromise the trustworthiness of their work (Steneck, Mayer, \& Anderson, 2010) and they should be free of personal and institutional biases. Researchers should also be aware of the consequences of research misconduct - they lose their reputation, credibility, funding, and above all, public trust in research also diminishes (Parry, 2014). They should be cognizant of the recent trend of academic papers getting retracted from 'prestigious' journals, which might suggest a crisis in scholarly publishing (Dylla, 2014). The cases of retraction are increasing due to author's dubious practices like fabrication, plagiarism, duplicate publication, salami publications, and reporting fraudulent research results (Steen, Casadevall, \& Fang, 2013). These remind authors to pay attention and reflect on their own practice - whether I am upholding integrity while doing this research.

Steneck (2006) views research practices in a spectrum - spreading from the ideal (responsible conduct of research) to the worst behaviour (deliberate misconduct) and captures questionable practices (fabrication, falsification and plagiarism, often referred to as 'FFP') in between. I however agree that researchers usually play in the middle for some time and step up towards ideal behaviour. Unfortunately, this will not be always the case, some may even slide down to the misconduct line. Therefore, our challenge is to ensure that researchers do not slide down into the misconduct lane. For this, individual researchers need to be vigilant personally, and we as research community should share our experiences supporting and critiquing each other's practices - all aiming to safeguard ethical research practices.

\section{Institutional Practices and Responsibilities}

Over the years, cases of scientific misconduct irrespective of scientific discipline are appearing with disconcerting frequency (Bando, Schaff, Sato, Kashimoto, \& Cameron, 2015). And widespread news of such cases have created public concern about research integrity. At its heart is the growing problem of misconduct in how we undertake our scientific inquiry and take shortcuts to getting 'popular', at the cost of gaining 'credibility'. Therefore, research integrity has been receiving a great deal of attention in the scholarly community because it is considered to have been eroding, and that the community urges that the integrity of scientific research be protected.

The responsibility for promoting research integrity lies also with research institutions as much as it does with the individual researchers. The institutions are responsible for ensuring compliance with good academic practice and for making institutional arrangements that 
can address cases of suspected violations of ethical research norms (Norwegian National Research Ethics Committees, 2014). They should demonstrate "a commitment to creating an environment that promotes responsible conduct by embracing standards of excellence, trustworthiness, and lawfulness and then assessing whether researchers and administrators perceive that an environment with high levels of integrity has been created" (National Academy of Sciences, 2002, p. 46). Given the importance of ethics for the conduct of research, it should come as no surprise that many different professional associations, government agencies, and universities have adopted specific codes, rules, and policies relating to research ethics. However, such practices are vaguely and sporadically practiced in Nepali institutions.

With research becoming an increasingly global pursuit, international efforts to promote research integrity are also increasing (Aschwanden, 2007; U.S. Department of Health and Human Services, Office of Research Integrity, 2009; Norwegian National Research Ethics Committees, 2016a). More particularly, many countries and research institutions are creating research integrity advisory boards and integrity offices (UK Research Integrity Office, Office for Research Integrity (ORI) USA, Scientific Integrity Committee of Swiss Academies of Sciences, Finnish Advisory Board on Research Integrity (1991), Japanese Association for the Promotion of Research Integrity (2016), Research Integrity and Auditing Office at Japan Society for the Promotion of Science). Such bodies support both institutional efforts and those of individual researchers. Such bodies' standards can be used by research institutions as codes of practice for research. Though a number of cases of research misconduct identified in universities by the University Grants Commission, and in everyday news, have put Nepali scholars' research practices under the spotlight, Nepal still lacks (there is a lack of specific offices to investigate suspected cases of misconduct and policies to deal with scientific dishonesty) a formal policy for reporting scientific misconduct (besides the court), and protecting whistle blowers.

It is high time our research institutions developed some frameworks for fostering integrity and curbing research misconduct. If they are not yet capable of creating their original guidelines, they can integrate the existing codes and guidelines such as Danish Code of Conduct for Research Integrity (Ministry of Higher Education and Science, 2014), Norwegian guidelines for research ethics (Norwegian National Research Ethics Committees, 2014, 2016a, 2016b), Singapore Statement on Research Integrity (Steneck, Mayer, \& Anderson, 2010) in their institutional frameworks.

Weighing on the above discussion, it may be useful to draw some ideas to foster responsible practice in Nepali research and publication context. First of all, we need to enhance university students' understanding of ethical issues in research. Therefore, institutional arrangements need to be made to educate research students on research integrity in general and on University's requirements on research integrity in particular right from undergraduate level. They should be made procedurally aware of the responsible 
conduct of research, and alarmed about potential pitfalls, including predatory and phony practices. Faculty should be equipped to deal with cases of academic dishonesty. Researchers and faculty should be discouraged to indulge in dubious research practices, including salami publication, partaking in rapacious conferences and publishing in miserly journals, for students also expect modelling of ethical behaviour by faculty and staff. Dubious publication practice can be discouraged in several ways. For example, article published in a "penny-pinching" journal may not be counted for appointments and promotions in academic jobs. Likewise, they should not be considered valid for meeting research publication criteria in academic degrees, especially at the post-graduate level. Moreover, universities and research institutions should take a lead and indicate where it is safe to publish and provide approved lists of journals and publishers.

Universities and research institutions in the country need to set up necessary organisational structure (perhaps, an independent research integrity board) to investigate misconduct allegations and to promote ethical conduct of research. They should have an ethics committee or at least a research integrity officer that/who plays an important role in maintaining standards of research and publication. This committee is often responsible for developing institutional policy to foster research integrity and for implementing this policy. It basically looks after the concerns in four areas; 1) promotion of responsible research environment in the university (for example, by a) educating and orienting faculty and staff on responsible practice of research - students want model behaviour from faculty; b) raising ethical awareness among students through dedicated courses and activities), 2) receiving and managing allegations of known or suspected academic and research misconduct by channelling appropriate expertise for a thorough evaluation; 3 ) publication ethics (including authorship, peer review, editorial and publishing ethics), and 4) monitor and audit research and maintain public accountability (making the annual report of its programs and activities public). As such, universities and research institutions should encourage education on research integrity, publication ethics and related matters (overall, responsible research practices) and also nurture an ethical research environment by providing regular mandatory responsible conduct of research (RCR) education and research integrity training to the wide range of personnel involved, including the faculty members, researchers, and graduate students.

Likewise, an independent authorised national ethics body, which may be called 'Research Integrity Advisory Board' or simply 'Research Board' to foster research integrity needs to be established. This body will be treated as an ultimate appellate scientific authority in the country, where we can report any suspected research misconduct, and also can access advice on ethical, legal and professionals standards in the practice of research. And as a monitoring body, it should also engage in detecting, investigating and punishing proven research misconduct in the country. It will support both institutional efforts and those of individual researchers. And its standards can be used by research institutions as 
Code of Practice for Research. For the time being, the University Grants Commission (UGC) can be authorised to do that. First of all, the board should develop guidelines or frameworks for research ethics - including for researchers, research educators, research institutions, research publishers, editors and peer reviewers. It is important that it focuses on integrity of both the agents (that participate in the process) and the research process itself (De Winter, 2016). It should focus on the overall environment of the research and the practice of the entire research community. It should develop criteria for evaluating individual and institutional research practices. It should develop a national indexing database and rank research institutions and journals providing them with some differentiated logos or seals based on their quality standards and adherence to research integrity guidelines. This body should also check the publication bazaar and inform the researchers about predatory conferences, journals and publishers, fake impact factors and misleading metrics. The research board should prepare guidelines for evaluating journals and should categorise journals published from institutions within the country. It should update the lists of approved journals in terms of the quality of peer review and adherence to ethical practices so that both the readers and authors could make informed choice about the quality and standard of the journal/papers. Likewise, it should also update the list of predatory, dubious or fake conferences, journals and publishers on a periodic basis.

Institutions publishing journals and other research outputs should have policies in place to deal with allegations of misconduct related to published articles (Iverson, Frankel, \& Siang, 2003, p. 146). It is therefore necessary for journals to espouse publication policies to ensure that ethical research is published, and that all necessary approvals regarding copyright transfer and license type have been agreed upon before publishing their work (John Wiley \& Sons, 2014). Moreover, the editorial offices must proactively guide their authors, reviewers and editors on expected ethical standards on respective fronts (Roberts, 2014). If publishers and journals want to ease their jobs, they can adopt some extant standard guidelines which are accepted to be useful to promote publication ethics (for example, Committee on Publication Ethics (COPE) guidelines (2016). In Nepali online journal publication context, it is high time Nepal Journals Online (NepJOL) editors formed an editorial alliance, and developed common guidelines to promote integrity in research publication. For example, it can develop policies like, yearly editorial office training for NepJOL editors; recognising best practice journal by peer reviewing journal's quality in peer review and editorial processes; barring authors from publishing in any NepJOL journals for up to three years in case of a proven violation of research integrity; and making the case of scientific misconduct visible by special editorial notices.

\section{Closing}

Ideally, safeguarding the ethics in the practice of research is the responsibility of all - researchers, research institutions, publishers and general public, and thus it requires 
the concerted effort of everyone engaged at each step of the knowledge chain. However, scientific community as the key player, should take a lead in discharging this responsibility. Therefore, this community should have in place a range of actions and measures to create a climate in which research integrity thrives (Bird, 2006). Our present need is to institutionalise research integrity through policies and procedures, and by establishing intact mechanism to curb academic dishonesty and to foster research integrity. Towards this direction, universities and research institutions should adopt both proactive (education and training on Responsible Conduct of Research, moral and value education, mentoring of early career researchers by senior academics, advice for whistle-blowers, etc.) and compliance (policy guidelines and codes of conduct, regulatory protocols, etc.) approaches to research integrity. Likewise, a national advisory body of research ethics needs to be set up or UGC can be authorised to promote research integrity and handle cases of research misconduct. Such an advisory body will be an autonomous committee to produce policy statement and regulatory protocols of ethical research principles and to implement them. Moreover, this advisory body, UGC, universities, research institutions and research publishers can come together in conversation to honestly commit to addressing research misconduct, and to institutionalise research integrity as a core, strategic value of the research institutions.

\section{References}

Alper, H. (2008). How can research integrity be best achieved? Materials Today, 11(4), 60. doi:10.1016/S1369-7021(08)70067-1

Aschwanden, C. (2007). Seeking an international dialogue on research integrity. Cell, 131, 109-111. doi:10.1016/j.cell.2007.09.032

Bando, K., Schaff, H. V., Sato, T., Hashimoto, K., \& Cameron, D. E. (2015). A multidisciplinary approach to ensure scientific integrity in clinical research. The Annals of Thoracic Surgery, 100(5), 1534-1536. doi:10.1016/j.athoracsur.2015.06.097

Bird, S. J. (2006). Research ethics, research integrity and the responsible conduct of research. Science and Engineering Ethics, 12(3), 411-412.

Bossi, E. (2010). Scientific integrity, misconduct in science. Swiss Medical Weekly, 140(1314), 183-186.

Committee on Assessing Integrity in Research Environments. (2002). Integrity in scientific research: Creating an environment that promotes responsible conduct. Washington, DC: National Academy of Sciences.

Committee on Publication Ethics. (2016). Promoting integrity in research and its publication. Retrieved from https://publicationethics.org/ 
10 R. K. Dhakal

De Winter, J. (2016). Interests and epistemic integrity in science: A new framework to assess interest influences in scientific research processes. Lanham, MD: Lexington Books.

Dylla, F. (2014, May 19). Scientific integrity. Retrieved from https://hub.wiley.com/comm unity/exchanges/discover/blog/2014/05/18/scientific-integrity?referrer=exchanges

Edwards, R., \& Mauthner, M. (2012). Ethics and feminist research: Theory and practice. In T. Miller, M. Birch, M. Mauthner, \& J. Jessop (Eds.), Ethics in qualitative research (2nd ed., pp. 14-28). New Delhi, India: Sage.

Iverson, M., Frankel, M. S., \& Siang, S. (2003). Scientific societies and research integrity: What are they doing and how well are they doing it? Science and Engineering Ethics, 9(2), 141-158.

John Wiley \& Sons. (2014). Best practice guidelines on publication ethics: A publisher's perspective (2nd ed.). Hoboken, NJ: Author.

Jalalian, M. (2015). The story of fake impact factor companies and how we detected them. Electronic Physician, 7(2), 1069-1072. doi:10.14661/2015.1069-1072

Khanyile, T., Duma, S., Fakude, L. P., Mbombo, N., Daniels, F., \& Sabone, M. S. (2006). Research integrity and misconduct: A clarification of the concepts. Curationis, 40-45.

Lins, L., \& Carvalho, F. M. (2014). Scientific integrity in Brazil. Journal of Bioethical Inquiry, 11(3), 283-287. doi:10.1007/s11673-014-9539-y

Macfarlane, B. (2009). Researching with integrity: The ethics of academic enquiry. New York, NY: Routledge.

Macrina, F. L. (2014). Scientific integrity: Text and cases in responsible conduct of research (4th ed.). Washington, DC: ASM Press.

Ministry of Education, Culture, Sports, Science and Technology. (2014). Guidelines for responding to misconduct in research. Tokyo, Japan: Author.

Ministry of Higher Education and Science. (2014). Danish code of conduct for research integrity. Copenhagen, Denmark: Author.

National Academy of Sciences. (2002). Integrity in scientific research: Creating an environment that promotes responsible conduct. Washington, DC: The National Academies Press.

Norwegian National Research Ethics Committees. (2014). General guidelines for research ethics. Oslo, Norway: Author.

Norwegian National Research Ethics Committees. (2016a). Guidelines for research ethics in the social sciences, humanities, law and theology (4th ed.). Oslo, Norway: Author.

Norwegian National Research Ethics Committees. (2016b). Guidelines for research ethics in science and technology (2th ed.). Oslo, Norway: Author. 
Parizeau, M-H. (1999). Scientific integrity. In A. Montefiore \& D. Vines (Eds.), Integrity in the public and private domains (pp. 152-165). London, England: Routledge.

Parry, J. (2014). Maintaining good research practice: Research integrity in the UK [Editorial]. Maturitas, 79, 239-240. doi:10.1016/j.maturitas.2014.08.010

Roberts, J. (2014, February 24). Publication ethics: The editorial office perspectives. Retrieved from https://hub.wiley.com/community/exchanges/discover/blog/2014/02/23/ publication-ethics-the-editorial-office-perspective?referrer=exchanges

Scanes, C. G. (2007). Ethics of publication: Is publication an obligation for researchers [Editorial]? Poultry Science, 86(10), 2051-2052. doi:10.1093/ps/86.10.2051

Shamoo, A. E., \& Resnik, D. B. (2015). Responsible conduct of research. Oxford, England: Oxford University Press.

Steen, R. G., Casadevall, A., Fang, F. C. (2013). Why has the number of scientific retractions increased? PLOS ONE, 8(7), e68397. doi:10.1371/journal.pone.0068397

Steneck, N. H. (2002). Assessing the integrity of publicly funded research. Investigating research integrity:Proceedings of the first ORI Research Conference on Research Integrity, 1-16.

Steneck N. H. (2006). Fostering integrity in research: Definitions, current knowledge, and future directions. Science and Engineering Ethics, 12, 53-74.

Steneck, N., Mayer, T., \& Anderson, M. (2010). Singapore statement on research integrity. Retrieved from https://wcrif.org/statement

U.S. Department of Health and Human Services, Office of Research Integrity. (2009). Responsible conduct of research. Retrieved from https:/ori.dhhs.gov/education/

U.S. National Institute of Health. (2012, February 6). Research integrity. Bethesda, MD: Office of Extramural Research. Retrieved from http://grants.nih.gov/grants/research integrity/index.htm 